\title{
The Adsorption of Rhodamine B in Water by Modified Zeolites
}

\author{
Wang-Yu Cheng ${ }^{1,2}$, Ning Li ${ }^{1,2}$, Yong-Zhang Pan ${ }^{1,2} \&$ La-Hua Jin ${ }^{1,2}$ \\ ${ }^{1}$ School of Environment, Jinan University, Guangzhou, China \\ ${ }^{2}$ Key Laboratory of Water/Soil Toxic Pollutants Control and Bioremediation of Guangdong Higher Education \\ Institutes, Jinan University, Guangzhou, China \\ Correspondence: Yong-Zhang Pan, School of Environment, Jinan University, Guangzhou, 510632, China. E-mail: \\ tpyz@jnu.edu.cn
}

Received: January 12, 2016

Accepted: January 22, 2016

Online Published: March 13, 2016

doi:10.5539/mas.v10n5p67

URL: http://dx.doi.org/10.5539/mas.v10n5p67

\begin{abstract}
In this study, modified zeolites were prepared through the modification of raw zeolites, using hydrochloric acid $(\mathrm{HCl})$ and cetyl trimethyl ammonium bromide $(\mathrm{CTAB})$, whose properties were then characterized by a Zeta Potential Meter and an X-ray diffractometer. Also, the adsorption mechanisms were investigated in depth. The experimental results indicated that, in terms of the adsorption capacity of Rhodamine B in water, the modified zeolites were more favorable than the raw zeolites. As the dosage of adsorbent increased, the removal percentage of Rhodamine $\mathrm{B}$ in the water increased, while the unit adsorption capacity decreased. The $\mathrm{pH}$ value of the solution, and reaction temperature imposed little effects on the adsorption of the Rhodamine B. In accordance with the adsorption thermodynamic results, Langmuir and Freundlich isothermal adsorption models were able to accurately describe the adsorption of Rhodamine B in water by the modified zeolites. The fitting results had a higher correlation when using a Freundlich isothermal model. At $303 \mathrm{~K}$, the static saturated adsorption capacity was $4.41 \mathrm{mg} / \mathrm{g}$. The kinetic results demonstrated that the adsorption of Rhodamine B in water using modified zeolites fit well with the pseudo-second-order kinetic model.
\end{abstract}

Keywords: zeolite modification, Rhodamine B, adsorption

\section{Introduction}

With the development of the dyeing industry, a great deal of dye wastewater is produced in China every year (Chen, Zhao, Wu, \& Dai, 2011; Hu, Chen, Ji, \& Yuan, 2010). Dye wastewater generally has a complex composition, high chemical oxygen demand (COD), high chromaticity, biochemical-degradation-resistant organic matter, and significant variations in water quality with the amount of water. These factors have made it difficult to treat the dye industry's wastewater. Rhodamine B is a type of artificially synthesized organic dye, which is currently widely used in many industries, such as papermaking, printing, textile dyeing, leather, paint, and so on(Das, Ghosh, Ghosh, \& Guha, 2008). However, it is carcinogenic. The common Rhodamine B removal processes include: physical-chemical, chemical, and biological methods, such as coagulant sedimentation(Sadri Moghaddam, Alavi Moghaddam, \& Arami, 2010), membrane separation(Sachdeva \& Kumar, 2009), adsorption(D. Karadag, Turan, Akgul, Tok, \& Faki, 2007), chemical oxidation(El-Desoky, Ghoneim, El-Sheikh, \& Zidan, 2010), ion exchange method(Labanda, Sabaté, \& Llorens, 2009), and aerobe and anaerobe degradation methods(Li, Zhang, Lin, Han, \& Lei, 2010). Among these, the adsorption method is regarded to be an effective method for the removal of dyes from water (Chatterjee, Lee, Lee, \& Woo, 2009).

Raw zeolites are a type of aluminosilicate crystals with skeletal structures, which can be easily obtained at low cost (Wang \& Peng, 2010). The removal of dyes from water using raw zeolites has aroused extensive attention (Hernández-Montoya, Pérez-Cruz, Mendoza-Castillo, Moreno-Virgen, \& Bonilla-Petriciolet, 2013; Widiastuti, $\mathrm{Wu}$, Ang, \& Zhang, 2011). The zeolites which are modified by a surface active agent can be used for the treatments of different types of ions, and make the treatment of wastewater with complex compositions possible. This modification using a surface active agent is a key technology for the application of raw zeolites in wastewater treatment (Leyva-Ramos et al., 2008; Zeng, Woo, Lee, \& Park, 2010). Currently, many research studies have investigated these modified zeolite's adsorption performances with many dyes, such as reactive black 5, reactive red 239, reactive yellow 176, acid orange 8, and acid orange II (Ayşegul, Ozgur, Abdullah Zahid, \& Mustafa, 2008; Benkli, Can, Turan, \& Çelik, 2005; Jin, Jiang, Shan, Pei, \& Chen, 2008; D. Karadag et 
al., 2007; Dogan Karadag, 2007; Torres-Pérez, Solache-Ríos, \& Olguín, 2007). However, few studies have been conducted regarding the removal of Rhodamine B in water using zeolites which have been modified by a surface active agent(Hayakawa, Dobashi, Miyamoto, \& Satake, 1997; Hayakawa et al., 2000).

In this study, modified zeolites were prepared by the modification of raw zeolites using hydrochloric acid (HCl) and cetyl trimethyl ammonium bromide (CTAB). The removal function of the modified zeolites on Rhodamine $\mathrm{B}$ in water was investigated using batch adsorption tests. The influencing factors of adsorption, as well as the related adsorption mechanisms were explored, with the aim of providing theoretical bases and basic data for the application of modified zeolites in the removal of Rhodamine B in water. Therefore, the present study can provide assistance for further development of high-efficiency, low-cost, environmentally friendly, and novel materials which can be used for dye wastewater treatments.

\section{Experiments}

\subsection{Experimental Reagents and Materials}

In this study, raw mordenite which was used had a purity of $60 \%$, and was purchased from Gongyi, China. The particle size of the raw mordenite was smaller than $0.15 \mathrm{~mm}$. The Rhodamine B was purchased from Tianjin, China. The $\mathrm{CTAB}$, sodium hydroxide $(\mathrm{NaOH})$, and $\mathrm{HCl}$ were the analytical reagents. The water used in the experiment was deionized.

\subsection{Analytical Instruments}

The instruments used in the present experiments included the following: a thermostat water bath (HH-2, Yuyao, China); constant-temperature shaking incubator (BS-1E, Changzhou, China); analytical balance (CP214C, Hangzhou, China); ultraviolet-visible spectrophotometer (TU-1810, Beijing, China); vacuum drying baker (DZF-6021, Shanghai, China); pH meter (WTW340I, Germany); desk-type high-speed centrifuge (TG16K-II, Jinan, China); X-ray diffractometer (MSAL-XD-2, Beijing, China); and Zeta potential measuring meter (Nano-ZS90, England).

\subsection{Experimental Methods}

\subsubsection{Preparation of the Modified Zeolites}

In this study's experiment, $10.0223 \mathrm{~g}$ CTAB (in a solid state) were precisely weighed, and then diluted with the deionized water to $500 \mathrm{~mL}$. Accordingly, a CTAB solution with a concentration of $0.055 \mathrm{~mol} / \mathrm{L}$ was prepared. A certain amount of raw zeolites was weighed and reacted with the $\mathrm{HCl}$ solution, with the concentration of $2 \mathrm{~mol} / \mathrm{L}$ in a water bath, during which the solid-to-liquid ratio was 1:10. The mixed solution was centrifuged for five minutes, at the rotating speed of $4000 \mathrm{r} \bullet \mathrm{min}^{-1}$. The solution was then repeatedly washed with deionized water until the eluate was $\mathrm{pH}$ neutral. The mixed solution was dried at $373 \mathrm{~K}$. A certain amount of the sample after drying was weighed and reacted with the CTAB solution, in accordance with the solid-to-liquid ratio of 1:10, for 4 hours in a water bath at $323 \mathrm{~K}$. The mixed solution was centrifuged for five minutes at the rotating speed of $4000 \mathrm{r}^{\circ} \mathrm{min}^{-1}$. Then, the solution was repeatedly washed with deionized water until no $\mathrm{Br}^{-}$was detected in $\mathrm{AgNO}_{3}$ solution. At this point, the mixed solution was dried at $323 \mathrm{~K}$, and then placed in a drying vessel for storage.

\subsubsection{Preparation of the Rhodamine B Solution}

In this experiment, $500 \mathrm{mg}$ of Rhodamine B (in a solid state) was precisely weighed and diluted to $500 \mathrm{~mL}$ with deionized water. For example, a Rhodamine B stock solution with a concentration of $1000 \mathrm{mg} / \mathrm{L}$ was prepared. Then, the Rhodamine B stock solution was diluted using deionized water, and a Rhodamine B solution with a concentration of $50 \mathrm{mg} / \mathrm{L}$ was prepared, in which the $\mathrm{pH}$ value was adjusted to a certain value using $\mathrm{HCl}$ or $\mathrm{NaOH}$ solutions with concentrations of $0.01 \mathrm{~mol} \cdot \mathrm{L}^{-1}$.

\subsubsection{Measurement of Zeta Potential}

At this point, $10 \mathrm{mg}$ samples from before and after the modification were dispersed in $50 \mathrm{~mL}$ of deionized water, with the $\mathrm{pH}$ values adjusted using $\mathrm{HCl}$ or $\mathrm{NaOH}$ solutions with concentrations of $0.01 \mathrm{~mol} \cdot \mathrm{L}^{-1}$. The mixed solution was shaken in a constant-temperature shaking incubator at the rotating speed of $180 \mathrm{r}^{\bullet} \mathrm{min}^{-1}$ so that the solution reached equilibrium. The Zeta potential was then measured using the potential measuring meter.

\subsubsection{Adsorption Experiments}

A Rhodamine B solution $(25 \mathrm{ml})$ was placed in a $100 \mathrm{~mL}$ conical flask, and a certain amount of modified zeolite or raw zeolite was added. Then, the conical flask was sealed using sealing film, and vibrated for a certain time in a constant-temperature shaking incubator at the rotating speed of $180 \mathrm{r} / \mathrm{min}$. A solid-liquid separation was 
conducted on the mixed solution in the conical flask by means of centrifugal separation. The concentration of the residual Rhodamine $\mathrm{B}$ in the supernate was then measured using an ultraviolet spectrophotometer, with a measurement wavelength of $554 \mathrm{~nm}$. The removal percentage $\eta(\%)$, and the unit removal capacity $q_{e}$ (with the unit of $\mathrm{mg} / \mathrm{g}$ ) could then be calculated by Eq. (1) and Eq. (2) as follows:

$$
\begin{gathered}
\eta=\left(\frac{C_{o}-C_{e}}{C_{o}}\right) \times 100 \% \\
q_{e}=\frac{\left(C_{o}-C_{e}\right) V}{m}
\end{gathered}
$$

In which $C_{o}$ denotes the concentration of Rhodamine $\mathrm{B}$ in the original solution, with the unit of $\mathrm{mg} / \mathrm{L}$; $C_{e}$ denotes the concentration of Rhodamine B in the solution after adsorption, with the unit of $\mathrm{mg} / \mathrm{L} ; V$ denotes the reaction volume, with the unit of $\mathrm{mL}$; and $m$ denotes the mass of the absorbent, with the unit of mg.

In the present study, the effects of the dosage of the modified zeolites, $\mathrm{pH}$ value of the solution, and reaction temperature on the adsorption results of Rhodamine B were investigated. The isothermal adsorption curves, along with the adsorption kinetics of the Rhodamine B using the modified zeolites were explored. In the experiments, each of the sample included two parallel samples, and one blank sample.

\section{Results and Discussion}

\subsection{X-Ray Diffraction (XRD) Patterns of the Zeolites before and after Modification}

In Figure 1 the XRD patterns of the raw and modified zeolites are displayed, respectively. It can be seen that, the phase patterns of the zeolites before and after the modification were similar, with almost identical peak positions and diffraction angles. The characteristics of the diffraction peaks in the raw zeolites were still preserved in the zeolites after modification, which suggested that the crystal structures of the zeolites after the modification using $\mathrm{HCl}$ and $\mathrm{CTAB}$ remain unchanged. For example, most of the CTAB molecules only coated the surface of the zeolite particles, rather than entering into the internal crystal framework.

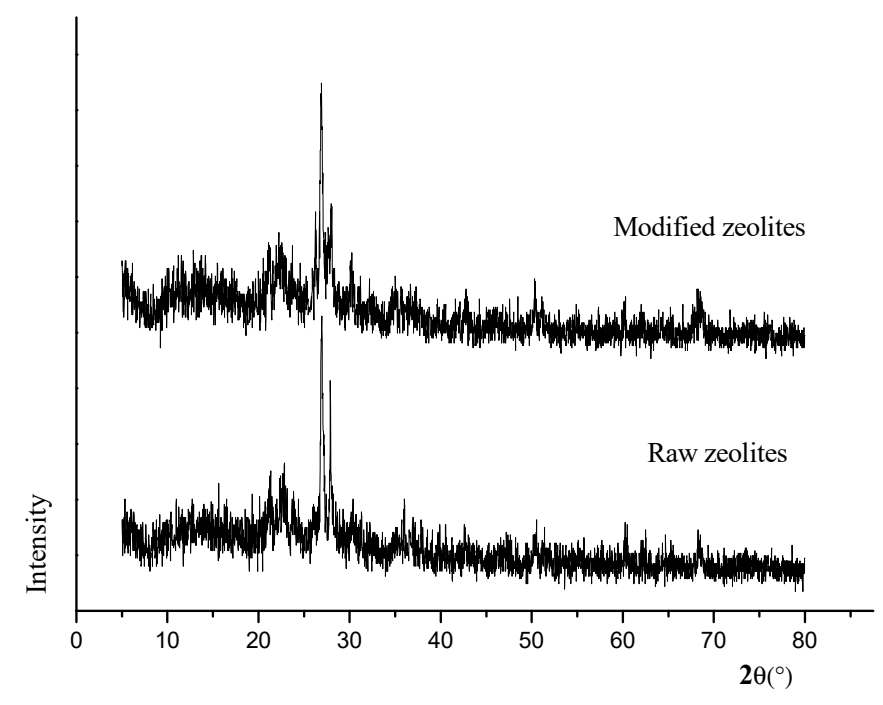

Figure 1. XRD patterns of the raw and modified zeolites

\subsection{Zeta Potentials of the Zeolites before and after Modification}

In Figure 2, the Zeta potential curves of the raw and modified zeolites, respectively, are displayed. It can be seen from the figure that the surfaces of the raw and modified zeolites carried negative charges when their $\mathrm{pH}$ values ranged from 3 to 12 . As the $\mathrm{pH}$ value of the solution increased, the negative charges on the surface increased. Moreover, when the $\mathrm{pH}$ values were the same, the negative charges on the surface of the raw zeolites were more, compared with those on the surface of the modified zeolites. 


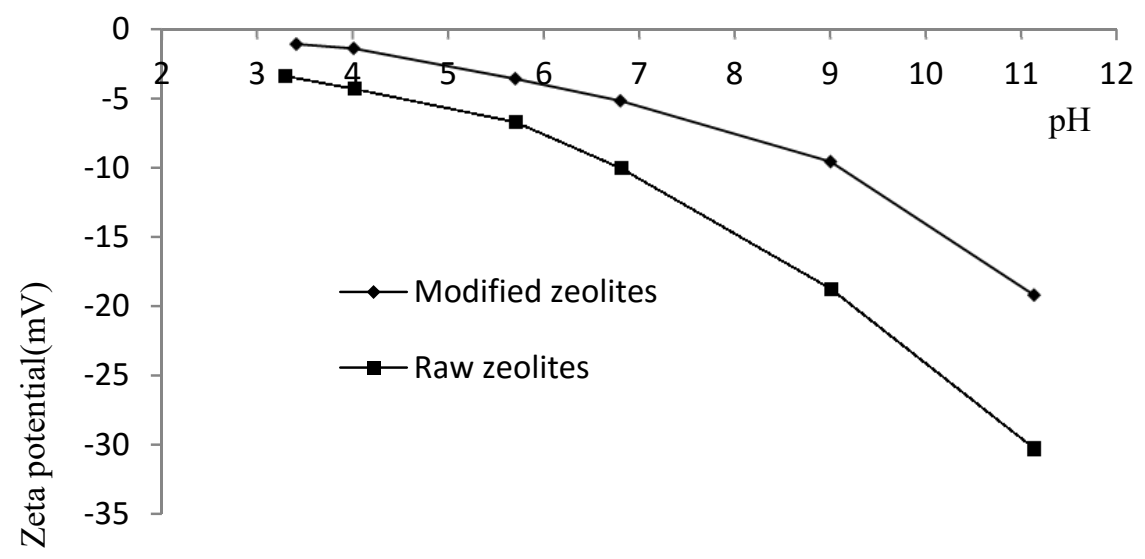

Figure 2. Zeta potential of the raw and modified zeolites

\subsection{Effects of the Dosage of Zeolites on the Removal Percentage of Rhodamine B}

Figure 3 displays the effects of the dosage of zeolites on the removal percentage of Rhodamine $\mathrm{B}$. When $\mathrm{C}_{0}=50$ $\mathrm{mg} / \mathrm{L}, \mathrm{T}=303 \mathrm{~K}, \mathrm{t}=24 \mathrm{~h}$, and $\mathrm{pH}=7$ (where $\mathrm{C}_{0}$ denotes initial mass concentration, $\mathrm{T}$ denotes reaction temperature, $\mathrm{t}$ denotes reaction duration, and $\mathrm{pH}$ denotes $\mathrm{pH}$ value of the solution), the removal percentage of Rhodamine B increased as the dosages of raw and modified zeolites increased. At a dosage of $16 \mathrm{~g} / \mathrm{L}$, the removal percentage of Rhodamine B using raw and modified zeolites reached $84.17 \%$ and $94.11 \%$, respectively. When the dosage was below $10 \mathrm{~g} / \mathrm{L}$, the removal percentage of Rhodamine B using the modified zeolites was found to be greater than that using the raw zeolites. The molecular size of Rhodamine B is bigger than the pore size of zeolite, therefore, Rhodamine B was primarily adsorbed by the surface of zeolites. According to the Zeta potential measurement results, the surface of the raw zeolites carried more negative charges, and the Rhodamine $\mathrm{B}$, which is a type of ionic dye, could be easily adsorbed via electrostatic adsorption. Negative charges also existed on the surface of the modified zeolites. For example, the electrostatic attraction also existed between the modified zeolites and Rhodamine B. However, in this case it was smaller than that between the raw zeolites and Rhodamine B. In regards to the modified zeolites, the adsorption mechanisms were primarily the hydrophobic interaction between the hydrophobic groups in the molecules of the Rhodamine B, and the hydrophobic ends in the CTAB. At a small dosage, the collision between the modified zeolites and Rhodamine B molecules had a low frequency, which led to a weak hydrophobic interaction between them. Therefore, the removal percentage of Rhodamine B using modified zeolites was found to be lower than that using raw zeolites. However, at a large dosage, the collision frequency between the modified zeolites and the Rhodamine B molecules gradually increased, and the hydrophobic interaction was gradually enhanced. Accordingly, the removal percentage of Rhodamine B using modified zeolites gradually increased. When the volume and concentration of the solution were fixed, with the increase of the dosage of the modified zeolites, the free active sites which were employed on the absorbent increased, and the unit adsorbing capacity of Rhodamine B in the solution using modified zeolites decreased.

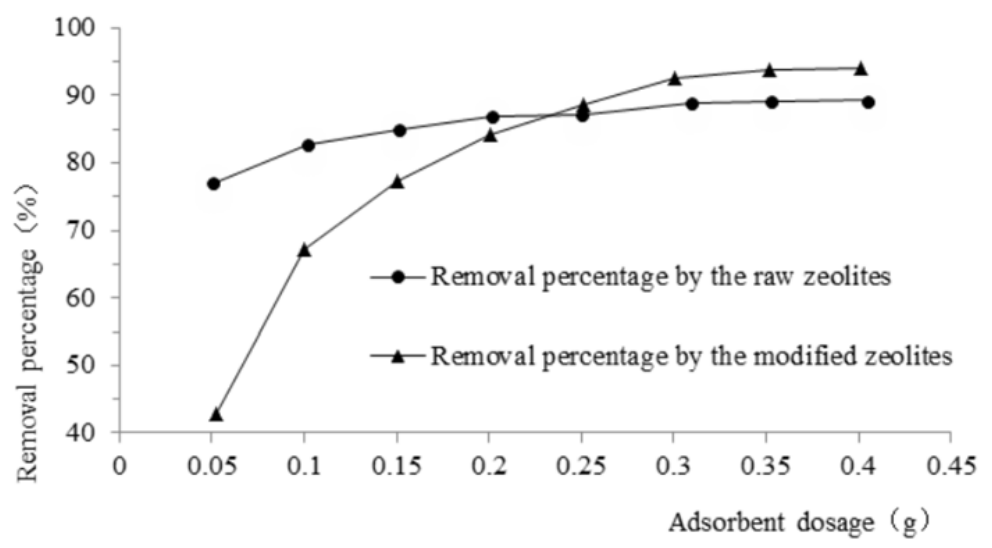

Figure 3. Effects of the adsorbent dosage on the removal percentage of Rhodamine B by the raw and modified zeolites 


\subsection{Effects of the pH Value of the Solution on the Adsorption of Rhodamine B Using the Modified Zeolites}

Figure 4 shows the effects of the $\mathrm{pH}$ value of the solution on the adsorption capacity of the modified zeolites for Rhodamine B. It can be seen from that figure that, when $\mathrm{C}_{0}=50 \mathrm{mg} / \mathrm{L}, \mathrm{m} / \mathrm{V}=10 \mathrm{~g} / \mathrm{L}, \mathrm{T}=303 \mathrm{~K}$ and $\mathrm{t}=24 \mathrm{~h}$ (where $\mathrm{m} / \mathrm{V}$ denotes the dosage of zeolites, and the other parameters were the same as listed above), and as the $\mathrm{pH}$ value increased from 3 to 11, it imposed little effect on the adsorption of Rhodamine B in the solution using the modified zeolites. In combination with the variation of the Zeta potential of the modified zeolites with the $\mathrm{pH}$ value, it was concluded in this study that the electrostatic attraction was not the main function which accounted for the adsorption of Rhodamine B using the modified zeolites.

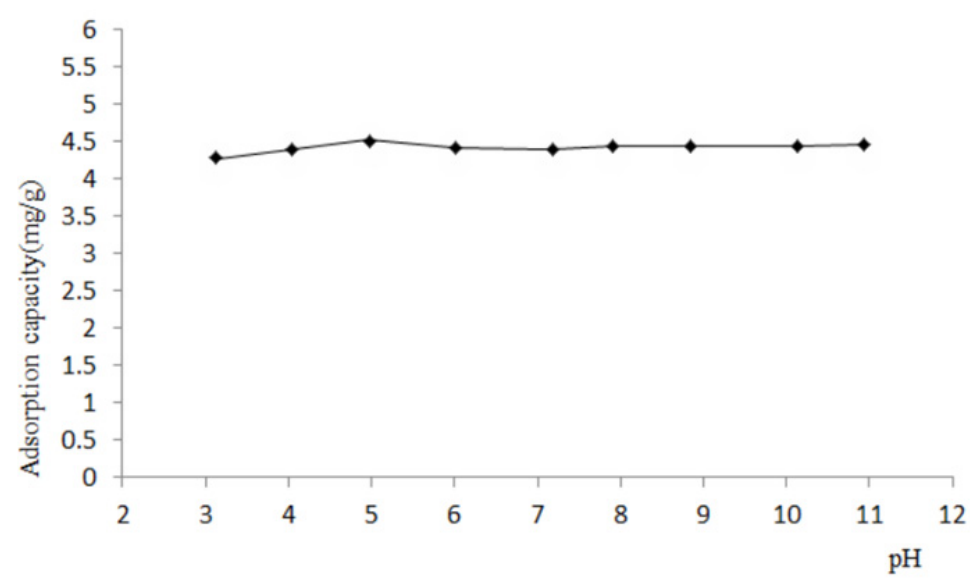

Figure 4. Effects of the $\mathrm{pH}$ on the adsorption capacity of Rhodamine B by the modified zeolites.

\subsection{Effects of the Reaction Temperature on the Adsorption of Rhodamine B Using Modified Zeolites}

Figure 5 displays the effects of temperature on the adsorption capacity of Rhodamine B using modified zeolites. When $\mathrm{C}_{0}=50 \mathrm{mg} / \mathrm{L}, \mathrm{m} / \mathrm{V}=10 \mathrm{~g} / \mathrm{L}, \mathrm{pH}=7$, and $\mathrm{t}=24 \mathrm{~h}$ (where parameters were the same as listed above), the unit adsorption capacity of the modified zeolites on the Rhodamine B in the solution was almost unchanged as the reaction temperature increased from $292 \mathrm{~K}$ to $313 \mathrm{~K}$. This indicated that, with the use of the modified zeolites, the reaction temperature had almost no effect on the adsorption of the Rhodamine $\mathrm{B}$ in the solution.

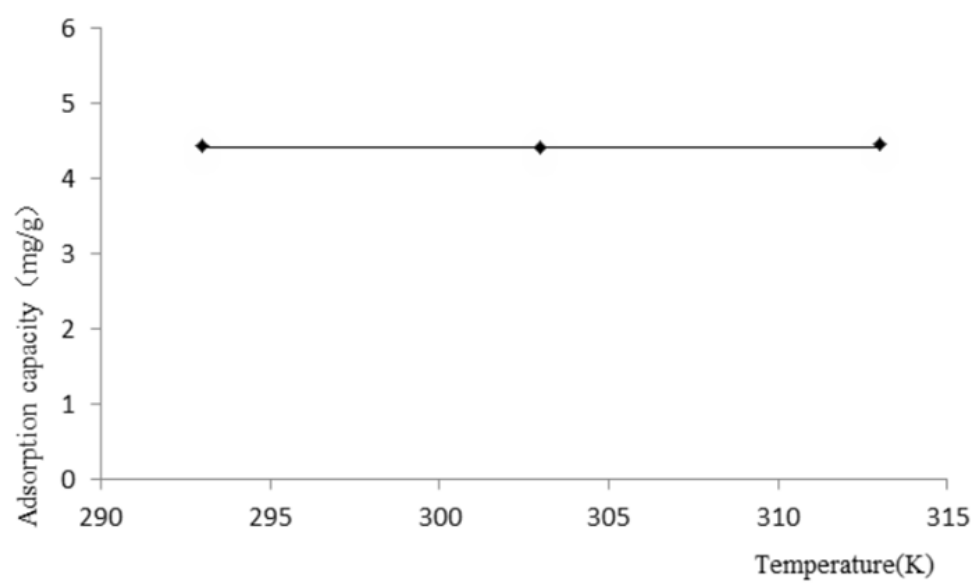

Figure 5. Effects of the reaction temperature on the adsorption capacity of Rhodamine B by the modified zeolites

\subsection{Isothermal Adsorption Curves of Rhodamine B Using Modified Zeolites}

The effects of the initial mass concentration on the adsorption of Rhodamine B using the modified zeolites can be seen in Figure 6. When $\mathrm{m} / \mathrm{V}=10 \mathrm{~g} / \mathrm{L}, \mathrm{t}=24 \mathrm{~h}, \mathrm{pH}=7$, and $\mathrm{T}=303 \mathrm{~K}$ (where parameters were the same as listed above), the adsorption capacity of Rhodamine B increased, while the removal percentage decreased with 
the increase of the initial mass concentration.

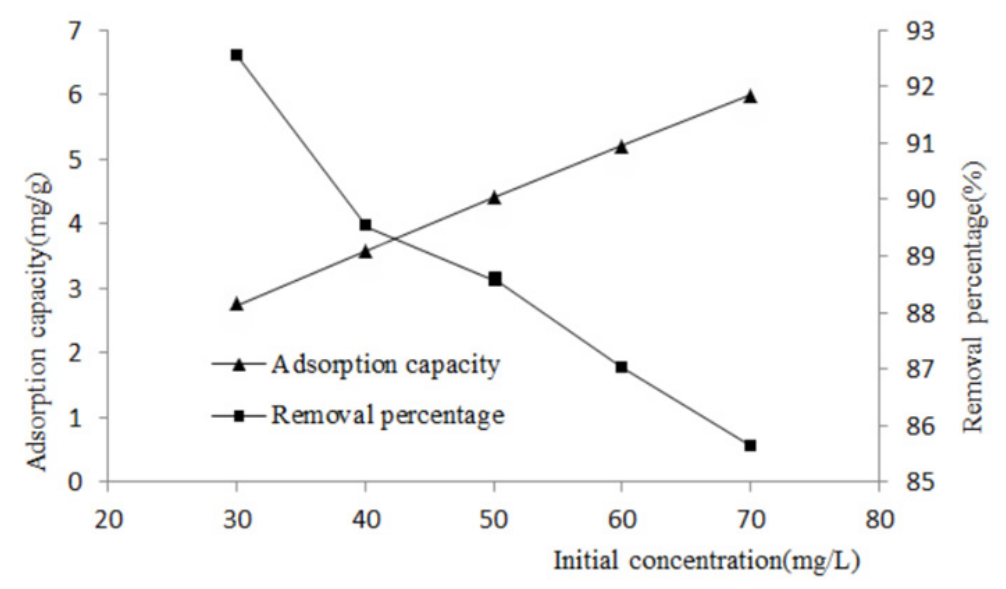

Figure 6. Effects of the initial concentration on the adsorption capacity and removal percentage of Rhodamine B by the modified zeolites

The data in Figure 6 were fitted using Langmuir and Freundlich adsorption isotherms, respectively.

The Langmuir adsorption isotherms can be described as follows:

$$
\frac{1}{q_{e}}=\left(\frac{1}{q_{m} k_{L}}\right) \frac{1}{c_{e}}+\frac{1}{q_{m}}
$$

In which $q_{e}$ denotes the adsorption capacity by the modified zeolites, with the unit of $\mathrm{mg} / \mathrm{g} ; c_{e}$ denotes the mass concentration of Rhodamine $\mathrm{B}$ after adsorption, with the unit of $\mathrm{mg} / \mathrm{L}$; and $k_{L}$ is the Langmuir adsorption constant, and $q_{m}$ reflects the theoretical maximum monolayer adsorption capacity of the adsorbent, with the unit of $\mathrm{mg} / \mathrm{g}$.

The Freundlich adsorption isotherms can be described as follows:

$$
\ln q_{e}=\lg k_{F}+\frac{1}{n} \ln c_{e}
$$

In which $q_{e}$ denotes the adsorption capacity of the modified zeolites, with the unit of $\mathrm{mg} / \mathrm{g}$; $c_{e}$ denotes the mass concentration of Rhodamine $\mathrm{B}$ after adsorption, with the unit of $\mathrm{mg} / \mathrm{L} ; k_{F}$ denotes the Langmuir adsorption constant, and $1 / \mathrm{n}$ denotes the adsorption strength.

The fitting results are shown in Figures 7 and 8, and the related parameters are listed in Table 1.

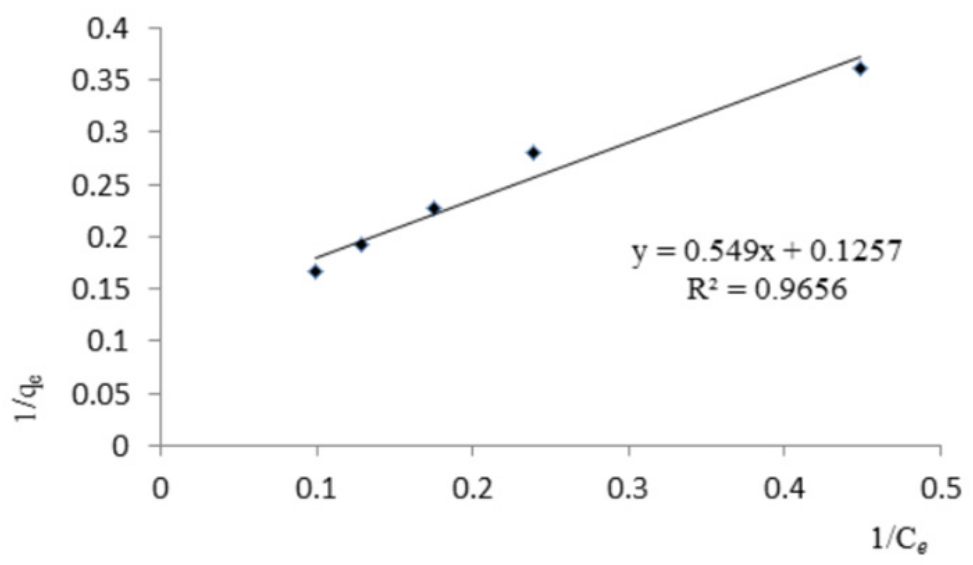

Figure 7. Fitting curve of the Langmuir equation 


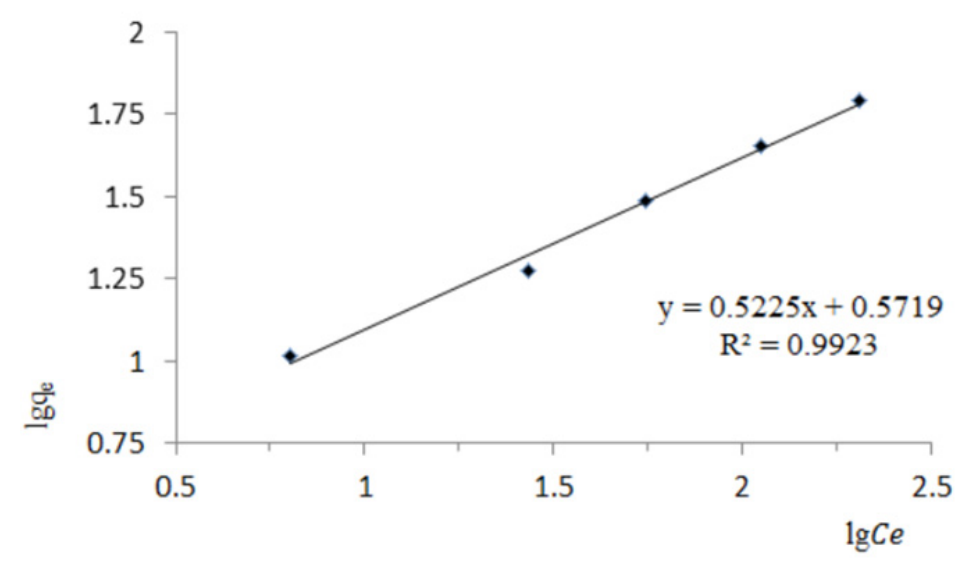

Figure 8. Fitting curve of the Freundlich equation

Table 1. Parameters of the Langmuir and Freundlich adsorption isotherms of Rhodamine B on the modified zeolites

\begin{tabular}{cccclc}
\hline \multicolumn{2}{c}{ Langmuir model } & \multicolumn{4}{c}{ Freundlich model } \\
\hline$q_{m}$ & $k_{L}$ & $R^{2}$ & $k_{F}$ & $1 / \mathrm{n}$ & $R^{2}$ \\
7.9554 & 0.2290 & 0.9656 & 1.7716 & 0.5225 & 0.9923 \\
\hline
\end{tabular}

As shown in Figure 7, Figure 8, and Table 1, the adsorption of Rhodamine B by the modified zeolites could be adequately fitted using both the Langmuir or Freundlich equations. The Langmuir equation is generally used for describing adsorption behaviors in which monolayer adsorption occupies a dominant role, or the adsorption occurs in diluted solutions (Yang \& Zhang, 2012). The Freundlich isothermal equation is used to describe the surface adsorption behaviors in which the adsorbate and adsorbent are combined by a chemical bond (Freundlich, 1906). Generally speaking, $1 / \mathrm{n} \leq 0.5$ denotes the case where the adsorbate is easily adsorbed, and $1 / \mathrm{n} \geq 2$ denotes the case where the adsorbate has difficulty being adsorbed. In this study, $1 / \mathrm{n}=0.5225$, which indicated that the adsorption of Rhodamine B was relatively easy.

\subsection{Adsorption Kinetics of Rhodamine B Using the Modified Zeolites}

The adsorption kinetic curve of Rhodamine $B$ in the solution by the modified zeolites is shown in Figure 9. It can be seen that, when $\mathrm{C}_{0}=50 \mathrm{mg} / \mathrm{L}, \mathrm{m} / \mathrm{V}=10 \mathrm{~g} / \mathrm{L}, \mathrm{pH}=7$, and $\mathrm{T}=303 \mathrm{~h}$ (where parameters were the same as listed above), the unit adsorption capacity of Rhodamine B in the solution by modified zeolites increased over the reaction time, until the adsorption equilibrium was reached.

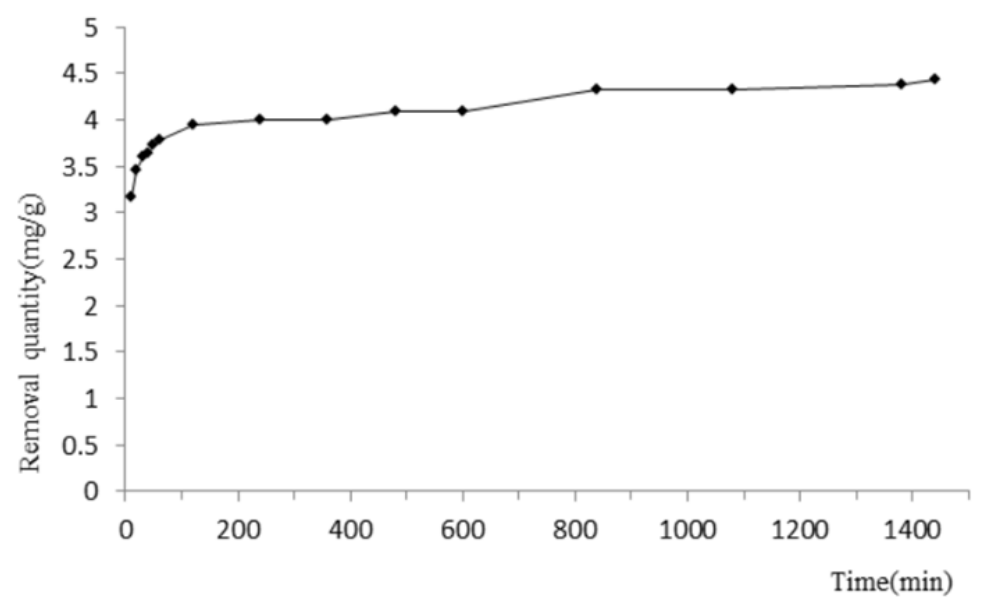

Figure 9. Effects of reaction time on the adsorption capacity of Rhodamine B by the modified zeolites

The data were fitted using a pseudo-second-order kinetic equation. 
This pseudo-second-order kinetic equation can be expressed as:

$$
\frac{t}{q_{t}}=\frac{1}{k_{2} q_{e}^{2}}+\frac{t}{q_{e}}
$$

In which $q_{e}$ and $q_{t}$ denote the unit adsorption capacities of Rhodamine B by the modified zeolites when the adsorption equilibrium was reached, and at $t$ moment, respectively, with the unit of $\mathrm{mg} / \mathrm{g}$; and $k_{2}$ denotes the pseudo-second-order adsorption velocity constant, with the unit of $\mathrm{g} /(\mathrm{mg} \cdot \mathrm{min})$.

Figure 10 presents the fitting results, and the related parameters are listed in Table 2.

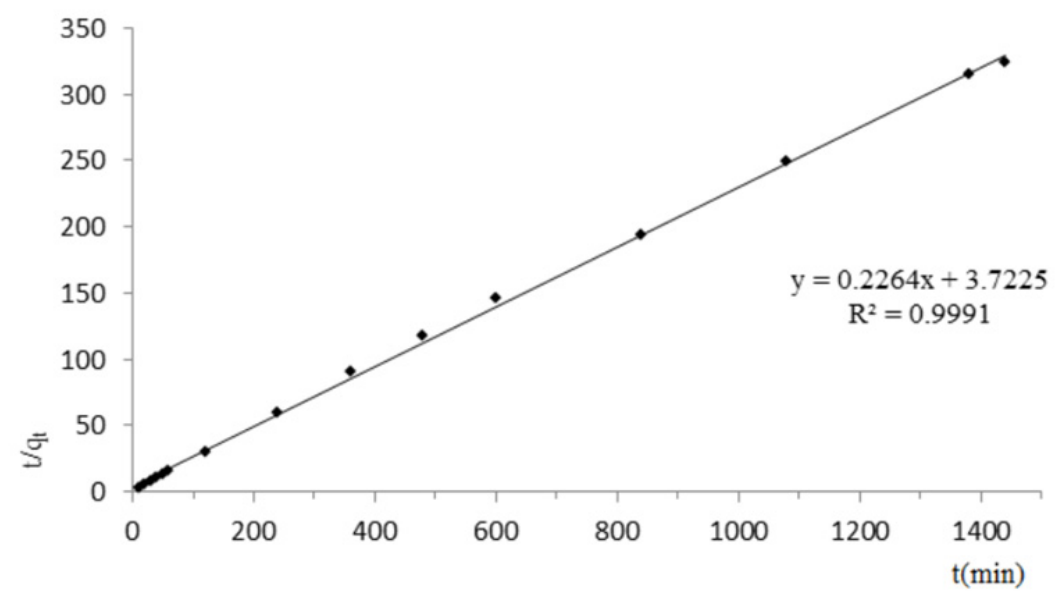

Figure 10. Pseudo-second-order adsorption kinetics of Rhodamine B by the modified zeolites

Table 2. Kinetic parameters for the adsorption of Rhodamine B by the modified zeolites

\begin{tabular}{ccc}
\hline$q_{e}$ & $k_{2}$ & $R^{2}$ \\
\hline 4.4228 & 0.0137 & 0.9991 \\
\hline
\end{tabular}

As shown in Figure 10 and Table 2, the fitting of the experimental data using the pseudo-second-order adsorption kinetic model had a fairly high correlation coefficient, which reached over 0.999 . Moreover, the calculated unit adsorption capacity in equilibrium state was very close to the experimental value. Accordingly, it can be concluded that the pseudo-second-order adsorption kinetic model could reasonably describe the adsorption kinetics of Rhodamine B in water using the modified zeolites.

\section{Conclusions}

(1) Modified zeolites were found to be superior to raw zeolites in the adsorption of Rhodamine B. The removal percentage of Rhodamine B increased as the dosage of adsorbent increased. The $\mathrm{pH}$ value of the solution, as well as the reaction temperature, imposed little effects on the adsorption of Rhodamine B using the modified zeolites.

(2) The surfaces of the zeolites before and after modification both carried negative charges. As the $\mathrm{pH}$ value of the solution increased, the negative charges on the surfaces increased. Under the same $\mathrm{pH}$ conditions, the quantity of negative charges on the surface of the raw zeolites was found to be greater than that on the surface of the modified zeolites.

(3) The adsorption equilibrium data of Rhodamine B using modified zeolites could be described using Langmuir and Freundlich isothermal equations. The pseudo-second-order kinetic model showed the ability to describe the adsorption kinetics of Rhodamine B in water using the modified zeolites.

Acknowledgments

This study was funded by Science and Technology Planning Project of Guangdong Province, China (No. 2013B031000001), and Scientific Research Foundation of Environmental Protection Bureau of Guangzhou City, China (No. 2014). 


\section{References}

Ayşegul, F., Ozgur, O., Abdullah, Z. T., \& Mustafa, T. (2008). Analysis of Fixed-Bed Column Adsorption of Reactive Yellow 176 onto Surfactant-Modified Zeolite. Industrial \& Engineering Chemistry Research, 47(18), 6999-7004.

Benkli, Y. E., Can, M. F., Turan, M., \& Çelik, M. S. (2005). Modification of organo-zeolite surface for the removal of reactive azo dyes in fixed-bed reactors. Water Research, 39(2/3), 487-493. http://dx.doi.org/10.1016/j.watres.2004.10.008

Chatterjee, S., Lee, D. S., Lee, M. W., \& Woo, S. H. (2009). Congo red adsorption from aqueous solutions by using chitosan hydrogel beads impregnated with nonionic or anionic surfactant. Bioresource Technology, 100(17), 3862-3868. http://dx.doi.org/10.1016/j.biortech.2009.03.023

Chen, H., Zhao, J., Wu, J. Y., \& Dai, G. L. (2011). Isotherm, thermodynamic, kinetics and adsorption mechanism studies of methyl orange by surfactant modified silkworm exuviae. Journal of Hazardous Materials, 192(1), 246-254. http://dx.doi.org/10.1016/j.jhazmat.2011.05.014

Das, S. K., Ghosh, P., Ghosh, I., \& Guha, A. K. (2008). Adsorption of rhodamine B on Rhizopus oryzae: Role of functional groups and cell wall components. Colloids and Surfaces. B, Biointerfaces, 65(1), 30-34. http://dx.doi.org/10.1016/j.colsurfb.2008.02.020

El-Desoky, H. S., Ghoneim, M. M., El-Sheikh, R., \& Zidan, N. M. (2010). Oxidation of Levafix CA reactive azo-dyes in industrial wastewater of textile dyeing by electro-generated Fenton's reagent. Journal of Hazardous Materials, 175(1-3), 858-865. http://dx.doi.org/10.1016/j.jhazmat.2009.10.089

Freundlich, H. (1906). Uber die Adsorption in Lösungen. Wilhelm Engelmann, Leipzig. Retrieved from http://worldcat.org /z-wcorg/ database

Hayakawa, K., Dobashi, A., Miyamoto, Y., \& Satake, I. (1997). Adsolubilization equilibrium of rhodamine B by zeolite/surfactant complexes. Studies in Surface Science and Catalysis., 105, 2115.

Hayakawa, K., Miyamoto, Y., Kurawaki, J., Kusumoto, Y., Satake, I., \& Sakai, M. (2000). Thermodynamics of the Adsolubilization Equilibrium of Rhodamine B by Surfactant-Modified Zeolites. Bulletin-Chemical Society of Japan, 73, 1777-1782.

Hernández-Montoya, V., Pérez-Cruz, M. A., Mendoza-Castillo, D. I., Moreno-Virgen, M. R., \& Bonilla-Petriciolet, A. (2013). Competitive adsorption of dyes and heavy metals on zeolitic structures. Journal of Environmental Management, 116, 213-221. http://dx.doi.org/10.1016/j.jenvman.2012.12.010

Hu, Z. H., Chen, H., Ji, F., \& Yuan, S. J. (2010). Removal of Congo Red from aqueous solution by cattail root. Journal of Hazardous Materials, 173(1-3), 292-297. http://dx.doi.org/10.1016/j.jhazmat.2009.08.082

Jin, X. Y., Jiang, M. Q., Shan, X. Q., Pei, Z. G., \& Chen, Z. L. (2008). Adsorption of methylene blue and orange II onto unmodified and surfactant-modified zeolite. Journal of Colloid \& Interface Science, 328(2), 243-247. http://dx.doi.org/10.1016/j.jcis.2008.08.066

Karadag, D. (2007). Modeling the mechanism, equilibrium and kinetics for the adsorption of Acid Orange 8 onto surfactant-modified clinoptilolite: The application of nonlinear regression analysis. Dyes \& Pigments, 74(3), 659-664. http://dx.doi.org/10.1016/j.dyepig.2006.04.009

Karadag, D., Turan, M., Akgul, E., Tok, S., \& Faki, A. (2007). Adsorption Equilibrium and Kinetics of Reactive Black 5 and Reactive Red 239 in Aqueous Solution onto Surfactant-Modified Zeolite. Journal of Chemical and Engineering Data., 52(5), 1615.

Labanda, J., Sabaté, J., \& Llorens, J (2009). Modeling of the dynamic adsorption of an anionic dye through ion-exchange membrane adsorber. Journal of Membrane Science, 340(1/2), 234-240. http://dx.doi.org/10.1016/j.memsci.2009.05.036

Leyva-Ramos, R., Jacobo-Azuara, A., Diaz-Flores, P. E., Guerrero-Coronado, R. M., Mendoza-Barron, J., \& Berber-Mendoza, M. S. (2008). Adsorption of chromium(VI) from an aqueous solution on a surfactant-modified zeolite. Colloids \& Surfaces A: Phys. Eng. Asp., 330(1), 35-41. http://dx.doi.org/10.1016/j.colsurfa.2008.07.025

Li, Z. J., Zhang, X. W., Lin, J., Han, S., \& Lei, L. H. (2010). Azo dye treatment with simultaneous electricity production in an anaerobic-aerobic sequential reactor and microbial fuel cell coupled system. Bioresource Technology, 101(12), 4440-4445. http://dx.doi.org/10.1016/j.biortech.2010.01.114 
Sachdeva, S., \& Kumar, A. (2009). Preparation of nanoporous composite carbon membrane for separation of rhodamine B dye. Journal of Membrane Science, $329(1 / 2), \quad 2-10$. http://dx.doi.org/10.1016/j.memsci.2008.10.050

Sadri, M. S., Alavi Moghaddam, M. R., \& Arami, M. (2010). Coagulation/flocculation process for dye removal using sludge from water treatment plant: Optimization through response surface methodology. Journal of Hazardous Materials, 175(1-3), 651-657. http://dx.doi.org/10.1016/j.jhazmat.2009.10.058

Torres-Pérez, J., Solache-Ríos, M., \& Olguín, M. T. (2007). Sorption of Azo Dyes onto a Mexican Surfactant-Modified Clinoptilolite-Rich Tuff. Separation Science \& Technology, 42(2), 299-318. http://dx.doi.org/10.1080/01496390601069879

Wang, S. B., \& Peng, Y. L. (2010). Raw zeolites as effective adsorbents in water and wastewater treatment. Chemical Engineering Journal, 156(1), 11-24. http://dx.doi.org/10.1016/j.cej.2009.10.029

Widiastuti, N., Wu, H. W., Ang, H. M., \& Zhang, D. K. (2011). Removal of ammonium from greywater using raw zeolite. Desalination, 277(1-3), 15-23. http://dx.doi.org/10.1016/j.desal.2011.03.030

Yang, Q., \& Zhang, H. J. (2012). Discussion on the Gaseous Slip Model Based on Langmuir Adsorption Isotherm. Physics Procedia Physics Procedia, 32(1), 179-183.

Zeng, Y. B., Woo, H., Lee, G. H., \& Park, J. (2010). Adsorption of Cr(VI) on hexadecylpyridinium bromide (HDPB) modified raw zeolites. Microporous \& Mesoporous Materials, 130(1-3), 83-91. http://dx.doi.org/10.1016/j.micromeso.2009.10.016

\section{Copyrights}

Copyright for this article is retained by the author(s), with first publication rights granted to the journal.

This is an open-access article distributed under the terms and conditions of the Creative Commons Attribution license (http://creativecommons.org/licenses/by/3.0/). 